\title{
Mechanisms of Arrhythmogenic Delayed and Early Afterdepolarizations in Ferret Ventricular Muscle
}

\author{
Eduardo Marban, * Shawn W. Robinson, and w. Gil Wier \\ Department of Physiology, The University of Maryland School of Medicine, and *Division of Cardiology, Department of Medicine, \\ The Johns Hopkins University School of Medicine, Baltimore, Maryland 21205
}

\begin{abstract}
Drug-induced triggered arrhythmias in heart muscle involve oscillations of membrane potential known as delayed or early afterdepolarizations (DADs or EADs). We examined the mechanism of DADs and EADs in ferret ventricular muscle. Membrane potential, tension and aequorin luminescence were measured during exposure to elevated $\left[\mathrm{Ca}^{2+}\right]_{0}$, strophanthidin and/or isoproterenol (to induce DADs), or cesium chloride (to induce EADs). Ryanodine $\left(10^{-9}-10^{-6} \mathrm{M}\right)$, an inhibitor of $\mathrm{Ca}^{2+}$ release from the sarcoplasmic reticulum, rapidly suppressed DADs and triggered arrhythmias. When cytoplasmic $\mathrm{Ca}^{2+}$-buffering capacity was enhanced by loading cells with the $\mathrm{Ca}^{2+}$ chelators BAPTA or quin2, DADs were similarly inhibited, as were contractile force and aequorin luminescence. In contrast to DADs, EADs induced by $\mathrm{Cs}$ were not suppressed by ryanodine or by loading with intracellular $\mathrm{Ca}^{2+}$ chelators. The possibility that transsarcolemmal $\mathrm{Ca}^{2+}$ entry might produce EADs was evaluated with highly specific dihydropyridine $\mathrm{Ca}$ channel agonists and antagonists. Bay K8644 (100-300 nM) potentiated EADs, whereas nitrendipine (3-20 $\mu \mathrm{M}$ ) abolished EADs. We conclude that DADs and DAD-related triggered arrhythmias are activated by an increase in intracellular free $\mathrm{Ca}^{2+}$ concentration, whereas EADs do not require elevated $\left[\mathrm{Ca}^{2+}\right]_{i}$ but rather arise as a direct consequence of $\mathrm{Ca}^{2+}$ entry through sarcolemmal slow Ca channels.
\end{abstract}

\section{Introduction}

Triggered arrhythmias in cardiac muscle occur in two distinct circumstances that point to fundamental differences in pathogenesis (1). The first type of triggered arrhythmia, which occurs prototypically during digitalis intoxication (2), is associated with membrane potential fluctuations known as delayed afterdepolarizations (DADs). ${ }^{1}$ DADs are secondary, unstimulated depolarizations that follow complete repolarization of an action potential. The mechanism of DADs has been the subject of intense

Address reprint requests to Dr. Marban, Division of Cardiology, The Johns Hopkins Hospital, Baltimore, MD 21205.

Presented in preliminary form at the scientific sessions of the American Heart Association, Washington, DC, November 1985. 1986.

Received for publication 29 January 1986 and in revised form 2 May

1. Abbreviations used in this paper: $\mathrm{DAD}$, delayed afterdepolarization; DMSO, dimethyl sulfoxide; EAD, early afterdepolarization; SR, sarcoplasmic reticulum.

J. Clin. Invest.

(c) The American Society for Clinical Investigation, Inc. $0021-9738 / 86 / 11 / 1185 / 08 \quad \$ 1.00$

Volume 78, November 1986, 1185-1192 investigation, and a consensus has emerged that excessive cellular $\mathrm{Ca}^{2+}$ loading establishes the milieu for DADs (3). Nevertheless, considerable uncertainty still surrounds the exact role of $\mathrm{Ca}^{2+}$. The link between sarcolemmal $\mathrm{Ca}^{2+}$ entry pathways and the DAD remains unclear, with controversy as to whether sarcolemmal $\mathrm{Ca}^{2+}$ entry $(4)$ or intracellular $\mathrm{Ca}^{2+}$ release $(5,6)$ is of primary importance.

The second type of triggered arrhythmia involves slowed or interrupted repolarization of the action potential, as observed in a number of models of the long QT syndrome (7-9). Such abnormalities of repolarization have been lumped together phenomenologically under the term "early afterdepolarizations" (EADs). Although EADs are protean (7), they can be distinguished from DADs because, by definition, EADs occur before action potential repolarization is complete, whereas DADs occur only after return to the resting potential (1). The mechanism of EADs is virtually unexplored, in contrast to that of DADs. EADs and DADs can coexist under some conditions (3); this indicates they might share a similar mechanism with variable kinetics. Indeed, it has been proposed that both DADs and EADs result from spontaneous oscillations of intracellular $\mathrm{Ca}^{2+}(10)$. Nevertheless, the two types of afterdepolarizations exhibit a very different dependence on stimulation frequency $(7,11)$ and on ionic conditions (1), indicating that the mechanisms may be quite dissimilar.

We have investigated the cellular mechanism of DADs and EADs in ferret ventricular muscle by examining their susceptibility to agents that act to antagonize intracellular $\mathrm{Ca}^{2+}$ overload. The first such agent is ryanodine, an alkaloid that inhibits $\mathrm{Ca}^{2+}$ release from the sarcoplasmic reticulum (SR)(12). Ryanodine antagonizes spontaneous (13) and triggered (14) oscillations of $\left[\mathrm{Ca}^{2+}\right]_{i}$ in heart cells, as well as aftercontractions associated with $\mathrm{Ca}^{2+}$ overload (15). The second type of agent is the $\mathrm{Ca}^{2+}$ chelator BAPTA (16). A noninvasive technique for loading with BAPTA is applied here for the first time in intact cardiac muscle. This novel method to increase the $\mathrm{Ca}^{2+}$-buffering capacity of the cytoplasm is characterized as a strategy to antagonize the intracellular $\mathrm{Ca}^{2+}$ fluctuations that occur during $\mathrm{Ca}^{2+}$ overload (13). Finally, evidence is presented that transsarcolemmal $\mathrm{Ca}^{2+}$ entry plays an important role in the genesis of EADs.

\section{Methods}

Experimental preparation. Ferrets 8-12 wk of age were anesthetized (Na pentobarbital, $50 \mathrm{mg} / \mathrm{kg}$ i.p.), and their hearts were removed rapidly via a midsternal thoracotomy. 22 preparations from a total of 19 animals were investigated. Papillary muscles $0.4-0.8-\mathrm{mm}$ diam were dissected from the right ventricle and mounted in a continuous-flow bath chamber, with the tendinous end attached to a tension transducer and the opposite end fixed (17). Preparations were field-stimulated with platinum wires connected to a stimulus isolation unit. Membrane potential was measured with respect to a grounded bath by using glass microelectrodes of 10 $20 \mathrm{M} \Omega$ resistance and a high input impedance electrometer (model KS700, WP Instruments, Inc., New Haven, CT). Membrane potential 
and tension were recorded on magnetic tape (3964A, Hewlett Packard Co., Palo Alto, CA), digitized (No. 4203, Princeton Applied Research, Princeton, NJ), and transmitted to a microcomputer (IBM PC/AT, IBM, Inc., Danbury, CT) for analysis. The sampling rate for digitization was optimized to display the relatively slow afterdepolarizations that are the focus of this study, limiting the resolution of faster events such as the action potential upstroke.

Solutions and pacing protocols. During a stabilization period of 1-2 $\mathrm{h}$, preparations were superfused with a physiological solution containing (in millimolar): $\mathrm{NaCl}, 92 ; \mathrm{Na}$ acetate, $20 ; \mathrm{NaHCO}_{3}, 20 ; \mathrm{Na}_{2} \mathrm{HPO}_{4}, 1$; $\mathrm{KCl}, 2.5 ; \mathrm{MgCl}_{2}, 1 ; \mathrm{CaCl}_{2}, 2$; and glucose, 10 . Solution $\mathrm{pH}$ was adjusted to $\mathrm{pH} 7.4$ by bubbling with $95 \% \mathrm{O}_{2} / 5 \% \mathrm{CO}_{2}$. All experiments were performed at $37^{\circ} \mathrm{C}$ unless otherwise indicated.

Ryanodine (Penick Corp., Lyndhurst, NJ) was added to the solutions by dilution of a 1-mM aqueous stock solution. All concentrations of ryanodine used exhibited similar antiarrhythmic effects at steady state, the major difference being that response to the drug was faster at higher concentrations. The dihydropyridines nitrendipine and Bay K8644, generously provided by the Miles Institute (New Haven, CT), were added as required from 1-mM stock solutions in polyethylene glycol.

DADs were induced by pacing at $2-3 \mathrm{~Hz}$ in trains lasting $10-20 \mathrm{~s}$ and sampled during the 2-5-s intervals betweet trains, in bathing solutions modified to favor $\mathrm{Ca}^{2+}$ overload $\left(\left[\mathrm{CaCl}_{2}\right]=5-10 \mathrm{mM}\right.$, strophanthidin, 3-10 $\mu \mathrm{M}$, and/or isoproterenol, 1-5 $\mu \mathrm{M})$. Strophanthidin and isoproterenol were purchased from Sigma Chemical Co., St. Louis, MO.

EADs were induced by pacing at $0.25-0.5 \mathrm{~Hz}$ during or after exposure to a solution containing $10-25 \mathrm{mM} \mathrm{CsCl}$ in addition to the usual constituents (cf. 7, 8). Although not a common cause of arrhythmias in the clinical setting, cesium toxicity induced in experimental animals has all of the hallmarks of the long QT syndrome. Exposure to Cs causes prolongation of the QT interval and polymorphic "Torsades des pointes" ventricular tachycardia $(8,9)$, the prototypical EAD-related arrhythmia. EADs elicited by $\mathrm{Cs}$ in Purkinje fibers $(7,9)$ share all the basic features of EADs that result from more "physiologic" interventions (e.g., low $\left[\mathrm{K}^{+}\right]_{0}$ and quinidine, ref. 18), but have the practical experimental advantage of being more readily and reproducibly inducible. Fig. 1 illustrates the various effects of exposure to $\mathrm{Cs}$ in ferret ventricular muscle and their dependence on the duration of exposure. Within 10-15 min, the membrane depolarized during diastole and action potential duration increased (panel $B$ ), as expected from the blockade of channels by $C s$ (19). Contractile force also increased, with the development of a "tonic" component. With more prolonged exposure to $\mathrm{Cs}(55 \mathrm{~min}, C)$, action potential duration increased markedly, while twitch force remained elevated relative to control. At the end of the long action potential plateau, membrane potential depolarized transiently prior to repolarization. This is an example of the type of EAD we have attempted to characterize (see Nomenclature).

The changes in membrane potential induced by exposure to Cs persisted for up to $60 \mathrm{~min}$ after the Cs was removed, such that stable EADs could often be produced during the washout of Cs. The response of each

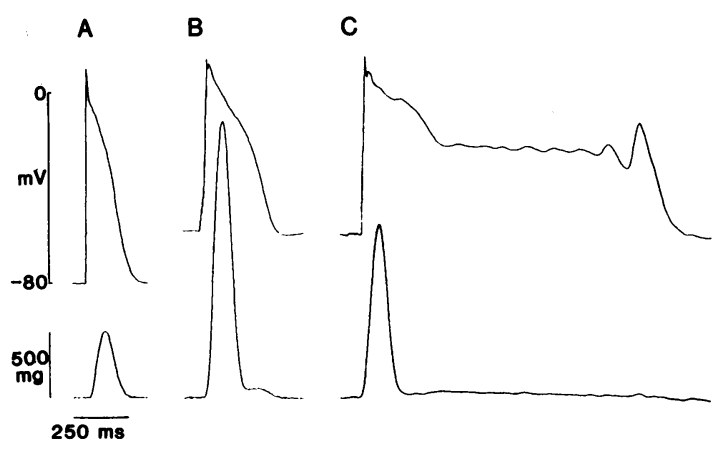

Figure 1. Effects of cesium on action potentials and force in ferret myocardium. $(A)$ Control action potential and twitch. $(B, C)$ During exposure to $10 \mathrm{mM} \mathrm{CsCl}(B) 14 \mathrm{~min} ;(C) 55 \mathrm{~min}$. muscle was somewhat variable in this regard, although repeated exposures to Cs gave consistent results within individual preparations.

$B A P T A$ loading procedure. Loading with $\mathrm{Ca}^{2+}$ chelator was achieved with the membrane-permeant acetoxymethyl ester of BAPTA, BAPTAAM (Molecular Probes, Eugene, OR). The ester diffuses freely into cells, where cytoplasmic esterases cleave off the AM groups, leaving the membrane-impermeant BAPTA in the cell (20). While flow was stopped transiently, BAPTA-AM was added directly to the bath at a concentration of 1-2 mM (from $50 \mathrm{mM}$ stock in dimethyl sulfoxide, DMSO). After 10-20 min, flow was restarted to wash out BAPTA-AM from the bath. The effects of BAPTA-loading on the action potential and twitch force are illustrated in Fig. 2. Prior to loading $(A)$, the preparation exhibits a strong twitch contraction during the action potential. The twitch was markedly attenuated after $20 \mathrm{~min}$ of exposure to BAPTA-AM $(B)$, along with a small but consistent depolarization of the action potential plateau. Twitch tension was generally depressed by $>80 \%$ after exposure to BAPTA-AM, but not during control experiments with DMSO alone. The negative inotropic effect of BAPTA was stable for 10-90 min (e.g., $14 \mathrm{~min}$ in Fig. $2 \mathrm{~B}$ ), after which time there was often a slow progressive recovery of the twitch (attributed to BAPTA leakage from the cells). In such cases, twitch force could again be attenuated by repeating the BAPTA loading procedure.

Quin2, a fluorescent derivative of BAPTA, was used as the $\mathrm{Ca}^{2+}$ chelator in some experiments. Quin2-AM (Calbiochem-Behring, La Jolla, CA) was applied to the bath in a manner identical to that described above for BAPTA. BAPTA and quin2 gave qualitatively similar results (compare Figs. 2 and 9), but BAPTA produced a more profound depression of the twitch, despite their rather similar dissociation constants for $\mathrm{Ca}$ (100 nM for BAPTA, versus $115 \mathrm{nM}$ for quin2; ref. 16).

Aequorin luminescence measurements. In some experiments, aequorin, a Ca ${ }^{2+}$-activated bioluminescent protein (21), was used to monitor changes in $\left[\mathrm{Ca}^{2+}\right]_{\mathrm{i}}$. Aequorin (purchased from Dr. J. Blinks, Mayo Clinic, Rochester, MN) was microinjected into 40-80 superficial cells, as described previously (17). Aequorin luminescence was conducted to the photocathode of a photomultiplier tube (EMI 9893B, Thorn EMI Gencom, Inc., Fairfield, NJ) via a Lucite light guide, quantified with photon counting techniques (13), and transferred to a microcomputer for data analysis and storage. Several consecutive transients were averaged to improve signal-to-noise ratio. The purpose of these experiments was to confirm that measured changes in tension reflected similar directional changes in $\left[\mathrm{Ca}^{2+}\right]_{i}$; therefore, only absolute aequorin luminescence was measured, and a specific calibration curve did not have to be assumed.

Nomenclature. The literature on after-potentials can be confusing because of ambiguities in nomenclature. Cranefield (1) has distinguished EADs and DADs as follows: "an early after-depolarization can be defined by the fact that it begins before repolarization is complete, and a delayed after-depolarization may be defined as a depolarization that appears only after repolarization has carried the membrane potential at least to the resting potential." Although there is little uncertainty in this definition of the DAD (see Fig. $3 \mathrm{~A}$ ), the definition of "early afterdepolarization"

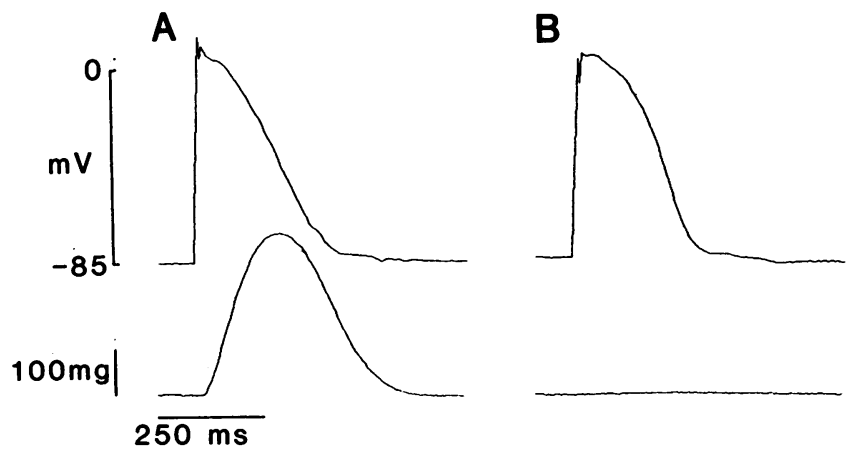

Figure 2. Loading with the $\mathrm{Ca}^{2+}$ chelator BAPTA reduces contractile force. $(A)$ Control action potential and twitch. $(B) 14 \mathrm{~min}$ after exposure to $1 \mathrm{mM}$ BAPTA-AM. Temperature $30^{\circ} \mathrm{C}$. 
leaves room for a number of protean events varying from slowing of the terminal phase of action potential repolarization (9), to secondary depolarizations occurring during the action potential plateau (e.g., the "low membrane potential EADs" of ref. 7). We have focused our attention on the latter type of EADs, which occur during phase 2 and involve an unambiguous depolarization (i.e., a definite period during which $d V / d t$ $>0$ ). These EADs are a consistent feature of Cs toxicity in ferret ventricular muscle (present paper) and in canine Purkinje fibers (7); similar afterpotentials have also been found in monophasic action potential recordings from patients with long QT syndrome (22).

\section{Results}

Fig. 3 shows membrane potential and force records obtained during exposure to elevated $\left[\mathrm{Ca}^{2+}\right]_{0}(10 \mathrm{mM})$ and $10 \mu \mathrm{M}$ strophanthidin, a cardiotonic steroid. The upper record in panel $A$ begins with the last three action potentials in a stimulated train, followed by DADs, the first three of which reach threshold to produce a triggered arrhythmia. The final oscillation in the membrane potential record is a DAD that fails to reach threshold. The tension record ( $A$, lower trace) shows that contractile fluctuations occur hand in hand with the DADs. Such aftercontractions have previously been correlated with DADs (2) and with the membrane current underlying the $\operatorname{DAD}(5,6)$, leading to the hypothesis that the DAD is activated by a rise in $\left[\mathrm{Ca}^{2+}\right]_{i}$. If this is true, then agents such as ryanodine, which decrease $\left[\mathrm{Ca}^{2+}\right]_{i}$, should antagonize DADs (15).

Exposure to $10^{-7} \mathrm{M}$ ryanodine rapidly inhibited the DAD and abolished the triggered arrhythmia, as shown in Fig. $3 B$. This inhibition occurred despite the continuing presence of elevated $\left[\mathrm{Ca}^{2+}\right]_{0}$ and strophanthidin, which normally led to progressive worsening of $\mathrm{Ca}^{2+}$ overload. Ryanodine abolished not only the afterdepolarizations, but also the associated aftercontractions, as expected if the primary site of action of ryanodine is the $\mathrm{Ca}^{2+}$ release mechanism of the sarcoplasmic reticulum.

A
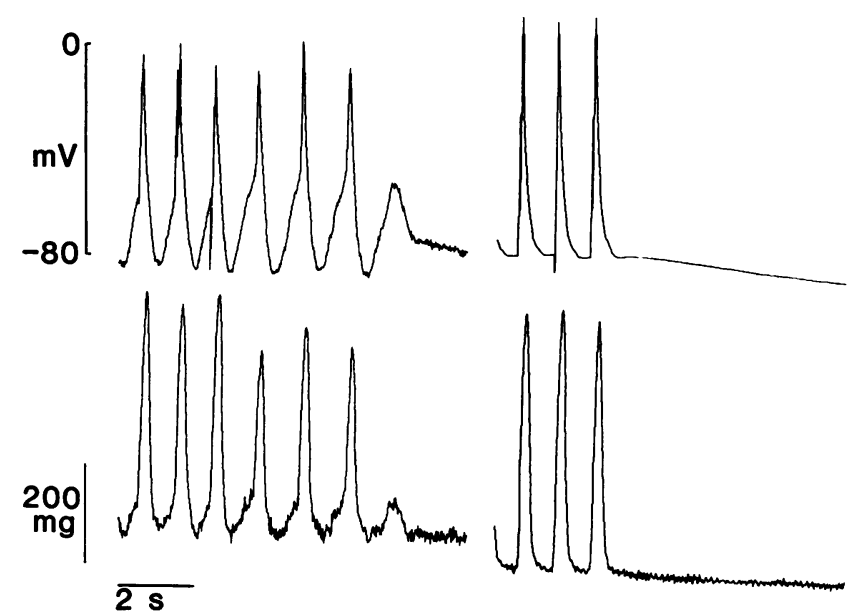

Figure 3. Effect of ryanodine on a triggered arrhythmia and delayed afterdepolarizations induced by exposure to strophanthidin $(10 \mu \mathrm{M})$ and $10 \mathrm{mM}\left[\mathrm{Ca}^{2+}\right]_{0}$. (A) Membrane potential (top) and tension at the end of a train of paced beats prior to addition of ryanodine. The first three action potentials and twitches are stimulated, and are followed by a triggered arrhythmia and DADs. $(B)$ After exposure to $10^{-7} \mathrm{M}$ ryanodine for $9 \mathrm{~min}$, in the continuing presence of strophanthidin and $10 \mathrm{mM}\left[\mathrm{Ca}^{2+}\right]_{0}$.
The inhibition of DADs by ryanodine is not restricted to digitalis-induced arrhythmias. Fig. 4 shows that ryanodine also antagonizes DADs induced by beta adrenergic stimulation. Panel $A$ illustrates membrane potential and tension during exposure to $1 \mu \mathrm{M}$ isoproterenol in $5 \mathrm{mM}\left[\mathrm{Ca}^{2+}\right]_{0}$. The first two and the last two beats in the record are stimulated; the third beat arises from a DAD that reaches threshold, and is followed by several subthreshold DADs. As before, the DADs are associated with aftercontractions. Exposure to a low concentration of ryanodine $\left(10^{-8} \mathrm{M}\right.$, panel $\left.B\right)$ resulted in virtually complete abolition of the DAD and the aftercontraction. These findings were confirmed in three experiments at ryanodine concentrations as low as $10^{-9} \mathrm{M}$.

The finding that ryanodine antagonizes drug-induced triggered arrhythmias and DADs is in agreement with previous observations that ryanodine (in higher concentrations) inhibits aftercontractions and DADs induced by $\mathrm{K}_{0}^{+}$withdrawal in Purkinje fibers (15), or by isoproterenol in the canine coronary sinus (23). Our findings confirm the previous work and additionally indicate that ryanodine is an effective antagonist of DAD-related triggered arrhythmias at concentrations as low as $10^{-9} \mathrm{M}$. We interpret our findings as follows. The primary event during these arrhythmias is intracellular $\mathrm{Ca}^{2+}$ overload, which produces oscillations of $\left[\mathrm{Ca}^{2+}\right]_{\mathrm{i}}$ manifested as aftercontractions. The DAD arises from an inward current pathway that is activated by the rise in $\left[\mathrm{Ca}^{2+}\right]_{i}$ $(5,6)$. Ryanodine interrupts this process by blocking the oscillatory release of $\mathrm{Ca}^{2+}$ by the $\mathrm{SR}$, thereby removing the stimulus that activates the DAD (15). If this hypothesis is true, increasing cytoplasmic $\mathrm{Ca}^{2+}$ buffering with $\mathrm{Ca}^{2+}$ chelators such as BAPTA would also be expected to antagonize DADs.

Effect of intracellular $\mathrm{Ca}^{2+}$ chelators on $\mathrm{DADs}$. Fig. 5 illustrates the effects of intracellular BAPTA on DADs induced by exposure to isoproterenol $(5 \mu \mathrm{M})$, strophanthidin $(3 \mu \mathrm{M})$, and $10 \mathrm{mM}\left[\mathrm{Ca}^{2+}\right]_{0}$. Panel $A$ shows membrane potential and tension prior to BAPTA loading, with two stimulated action potentials followed by a series of DADs and aftercontractions. The muscle was then loaded with BAPTA during continued exposure to the drug-containing, high $\left[\mathrm{Ca}^{2+}\right]_{0}$ solution. The records in panel $\mathrm{B}$ were obtained 2 min after washing out BAPTA-AM. BAPTAloading produced a dramatic abolition of the DAD, and a marked
A
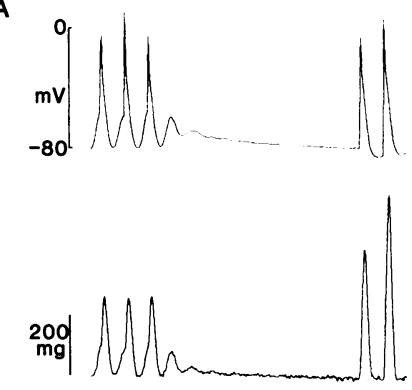

B
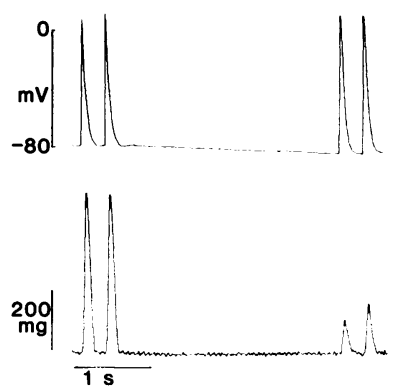

Figure 4. Triggered arrhythmogenesis induced by beta adren$\left[\mathrm{Ca}^{2+}\right]_{0}$ : inhibition by ryanodine. Bathing solution in both panels contained $5 \mathrm{mM}\left[\mathrm{Ca}^{2+}\right]_{0}$ and $1 \mu \mathrm{M}$ isoproterenol. $(A)$ Membrane potential (top) and tension prior to ryanodine. The first two and the last two beats are stimulated. Between these are an extrasystole and several subthreshold DADs. (B) 36 min after adding $10^{-8} \mathrm{M}$ ryanodine to the bathing solution. ergic stimulation and elevated 

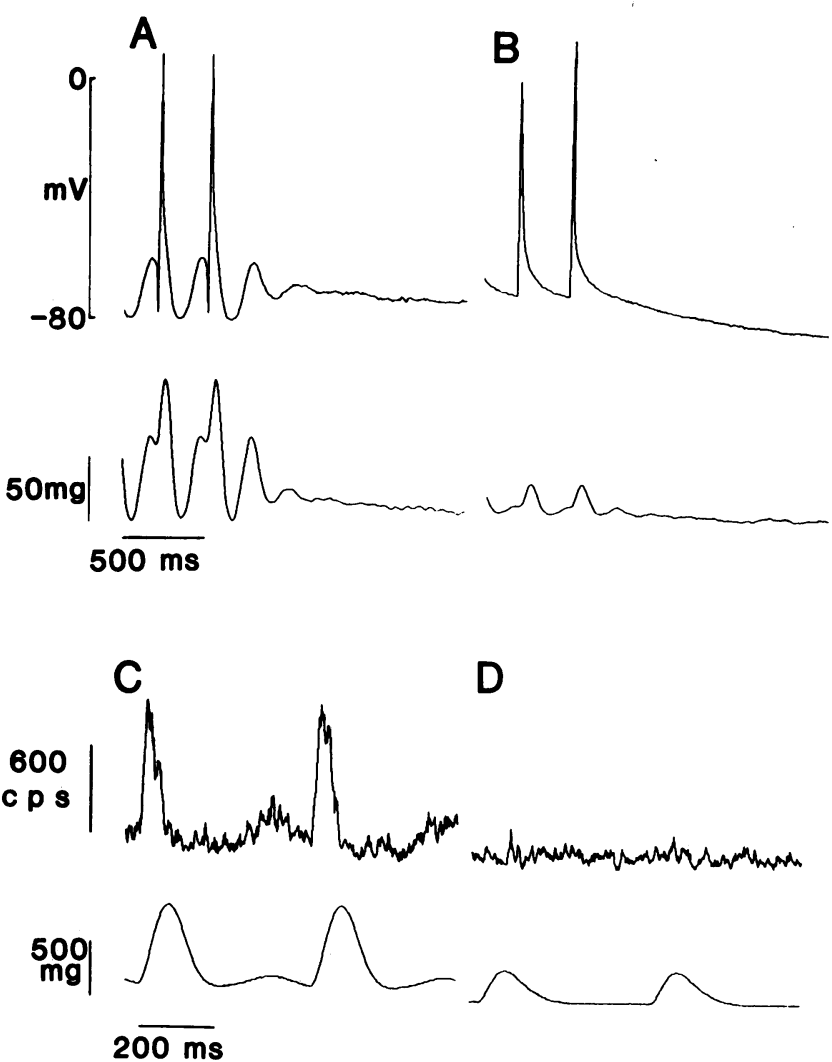

Figure 5. Delayed afterdepolarizations and $\left[\mathrm{Ca}^{2+}\right]_{\mathrm{i}}$ oscillations suppressed by the intracellular $\mathrm{Ca}^{2+}$ chelator BAPTA. Bathing solution in all panels contained isoproterenol $(5 \mu \mathrm{M})$, strophanthidin $(3 \mu \mathrm{M})$ and $10 \mathrm{mM}\left[\mathrm{Ca}^{2+}\right]_{0} .(A)$ End of a stimulated train of action potentials (top) and twitches, followed by DADs and aftercontractions, prior to loading with BAPTA. (B) 2 min after loading with $1 \mathrm{mM}$ BAPTA-AM for 13 min. $30^{\circ} \mathrm{C} .(C, D)$ Depression of aequorin luminescence and tension oscillations by BAPTA. $(A)$ Prior to BAPTA loading. 101 sweeps averaged. $(B)$ after loading with $1 \mathrm{mM}$ BAPTA-AM for $15 \mathrm{~min} .151$ sweeps averaged.

attenuation of contractile force, despite the continued presence of isoproterenol, strophanthidin, and elevated $\left[\mathrm{Ca}^{2+}\right]_{0}$. This effect of BAPTA was confirmed in two other preparations, and was also seen with quin2. These results indicate that augmentation of intracellular $\mathrm{Ca}^{2+}$ buffering power can attenuate $\mathrm{Ca}^{2+}$ oscillations and their electrophysiologic sequelae.

Previous experiments with aequorin have shown that ryanodine decreases $\left[\mathrm{Ca}^{2+}\right]_{\mathrm{i}}$ as the mechanism of its negative inotropic effect in ferret ventricular muscle (17). To ascertain whether the negative inotropic effect of BAPTA was likewise attributable to a decrease in $\left[\mathrm{Ca}^{2+}\right]_{i}$, we observed its effects on $\mathrm{Ca}^{2+}$-activated aequorin luminescence (Fig. $5 \mathrm{C}$ and $D$ ). Panel $C$ illustrates aequorin luminescence (upper row) and tension during $\mathrm{Ca}^{2+}$ overload induced as in panel $A$. Both the aequorin luminescence and force recordings exhibit characteristic oscillations (24), attributable to oscillations of $\left[\mathrm{Ca}^{2+}\right]_{i}$, that follow each of the two stimulated twitches. After BAPTA loading (D), aequorin luminescence and force are both greatly attenuated, and no oscillatory after events are present. The results confirm that $\left[\mathrm{Ca}^{2+}\right]_{\mathrm{i}}$ is decreased when tension falls after BAPTA loading. Aequorin luminescence appears to be attenuated more than tension. Several factors might contribute to the disproportionate decrease in aequorin light. First of all, BAPTA loading may be more efficient in the superficial cells of the preparation, from which aequorin luminescence is measured, than in the deeper cells, which generate most of the tension. Secondly, the marked fall in $\mathrm{Ca}^{2+}$-sensitivity of aequiorin as $\left[\mathrm{Ca}^{2+}\right]$ decreases $(21)$ would tend to accentuate the differences between force and aequorin light. Thirdly; twitch tension can decline during $\mathrm{Ca}^{2+}$ overload without a concomitant decrease in aequorin luminescence (24). We can exclude the possibility that all the aequorin has been consumed, since similar attenuation of the aequorin signal and force in another trial was overcome by increasing $\left[\mathrm{Ca}^{2+}\right]_{0}$ (data not shown). A direct attenuation of aequorin luminescence by BAPTA, while not impossible, appears unlikely in view of the lack of such attenuation by several other chelators (EGTA, EDTA, and CDTA; ref. 21) that are closely related chemically to BAPTA (16).

Taken together, the effects of ryanodine and BAPTA provide strong evidence that intracellular $\mathrm{Ca}^{2+}$ overload is primarily responsible for DAD-related triggered arrhythmias. Both ryanodine and BAPTA act to decrease intracellular $\mathrm{Ca}^{2+}$ and antagonize DADs, despite a constant $\left[\mathrm{Ca}^{2+}\right]_{0}$. This finding provides strong evidence that $\mathrm{Ca}^{2+}$ activates the current, and that its primary role is not as a charge carrier.

Is increased $\left[\mathrm{Ca}^{2+}\right]_{i}$ obligatory for EADs? In contrast to DADs, the basic mechanism of EADs remains unclear. One possibility is that they are activated in a similar fashion to DADs; in this case, the differences in their shape and time course might arise from differences in $\left[\mathrm{Ca}^{2+}\right]_{i}(10)$. Several observations are consistent with this hypothesis. First of all, a positive inotropic effect occurs upon exposure to Cs, as illustrated in Fig. 1. Such a positive inotropic effect was observed consistently in all 10 preparations exposed to Cs. This suggests that EADs might be favored in a setting of increased $\left[\mathrm{Ca}^{2+}\right]_{i}$.

Another observation hinting that $\mathrm{Ca}^{2+}$ may play an important role in generating the EAD is shown in Fig. 6. Panel $A$ shows the action potential and force just after returning to control solution in a muscle that had been exposed to Cs (10 mM) for 60 min. The action potential is markedly prolonged, with a small EAD ( $5 \mathrm{mV}$ in amplitude) occurring at the end of the plateau. $\left[\mathrm{Ca}^{2+}\right]_{0}$ was then doubled (to $4 \mathrm{mM}$ ). As shown in panel $B$, twitch force increased in response to the increase in $\left[\mathrm{Ca}^{2+}\right]_{0}$, and the tonic component of force became more prominent. Despite an overall decrease in action potential duration, the amplitude of the EAD increased dramatically (to $15 \mathrm{mV}$ ) in elevated $\left[\mathrm{Ca}^{2+}\right]_{0}$. All these effects were reversed when the muscle was

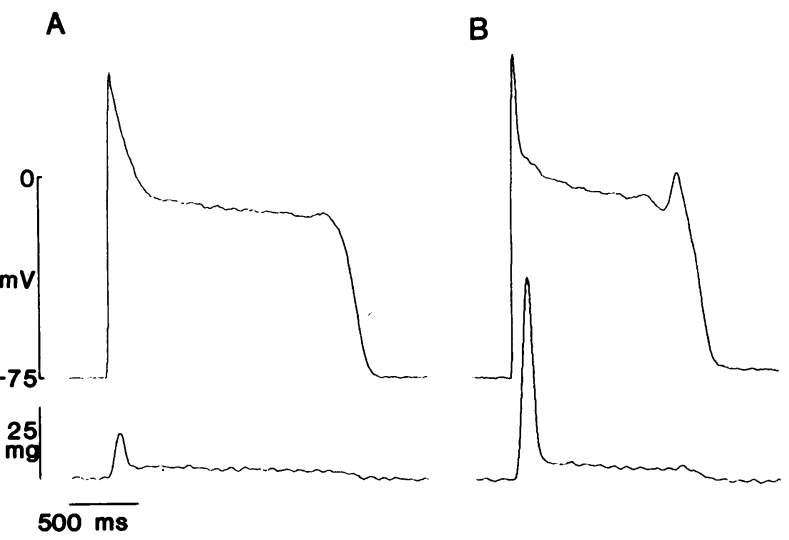

Figure 6. Potentiation of EADs by elevated $\left[\mathrm{Ca}^{2+}\right]_{0}$. (A) Action potential and force $6 \mathrm{~min}$ after exposure to $10 \mathrm{mM} \mathrm{Cs}$, in standard solution containing $2 \mathrm{mM}\left[\mathrm{Ca}^{2+}\right]_{0}$. (B) During exposure to $4 \mathrm{mM}\left[\mathrm{Ca}^{2+}\right]_{0}(2 \mathrm{~min})$. 
returned to $2 \mathrm{mM}\left[\mathrm{Ca}^{2+}\right]_{0}$, and occurred once again when $\left[\mathrm{Ca}^{2+}\right]_{0}$ was increased (not shown). The potentiation of EADs by increasing $\left[\mathrm{Ca}^{2+}\right]_{0}$ was confirmed in two experiments.

The results in Figs. 1 and 6 are consistent with either of two distinct hypotheses relating $\mathrm{Ca}^{2+}$ to the genesis of EADs. The first of these is that EADs are just DADs in another guise: they result from sarcolemmal inward current channels activated by increased $\left[\mathrm{Ca}^{2+}\right]_{\mathrm{i}}$. In this case, the EADs should be inhibited by interventions targeted at $\left[\mathrm{Ca}^{2+}\right]_{i}$ (ryanodine and intracellular $\mathrm{Ca}^{2+}$ chelators). The second possibility is that $\mathrm{Ca}^{2+}$ entry via sarcolemmal $\mathrm{Ca}^{2+}$ channels is of primary importance and directly produces the depolarization. In this case $\mathrm{Ca}^{2+}$ would play an important role as a charge carrier, but not as an intracellular signal. If EADs were mediated by the second mechanism, they would not be inhibited by ryanodine, BAPTA, or quin2, but might well be sensitive to dihydropyridine $\mathrm{Ca}$ channel agonists and antagonists (such as Bay K8644 and nitrendipine).

To distinguish between the activating mechanisms of EADs and DADs, we determined the effect of ryanodine on EADs. Fig. $7 A$ shows the action potential and force after exposure to $10 \mathrm{mM} \mathrm{Cs}$, in $4 \mathrm{mM}\left[\mathrm{Ca}^{2+}\right]_{0}$ to potentiate EADs. Ryanodine (1 $\mu \mathrm{M})$ was then added to the superfusing solution. Although force was dramatically attenuated by ryanodine $(B)$, the EAD was not inhibited; indeed, a small potentiation was apparent. This result, which was confirmed in two experiments, suggests that increased $\left[\mathrm{Ca}^{2+}\right]_{\mathrm{i}}$ is not obligatory for the genesis of EADs.

We sought confirmation of this idea by examining the susceptibility of EADs to intracellular $\mathrm{Ca}^{2+}$ chelators. Fig. $8 \mathrm{~A}$ shows the action potential and force in control solution prior to BAPTA loading. The muscle was then loaded with BAPTA and exposed to $25 \mathrm{mM} \mathrm{Cs}$, as shown in panel $B$. EADs were still readily inducible, although $\left[\mathrm{Ca}^{2+}\right]_{\mathrm{i}}$ was heavily buffered (as evidenced by the marked attenuation of contractile force). These results were confirmed in three other preparations, and were also observed after quin2 loading (e.g., Fig. 9).

EADs: role of $\mathrm{Ca}^{2+}$ entry via sarcolemmal Ca channels. The lack of inhibition of EADs by ryanodine or by intracellular $\mathrm{Ca}^{2+}$ chelators provides strong evidence that increased $\left[\mathrm{Ca}^{2+}\right]_{i}$ is not required for the genesis of EADs. The alternative hypothesis, i.e., that $\mathrm{Ca}^{2+}$ entry plays a dominant role, was tested with highly selective pharmacologic modulators of $\mathrm{Ca}$ channel gating properties. Bay K8644 acts as a potent agonist on slow Ca channels, increasing their open state probability upon depolarization. $\mathrm{Ni}$ -

A

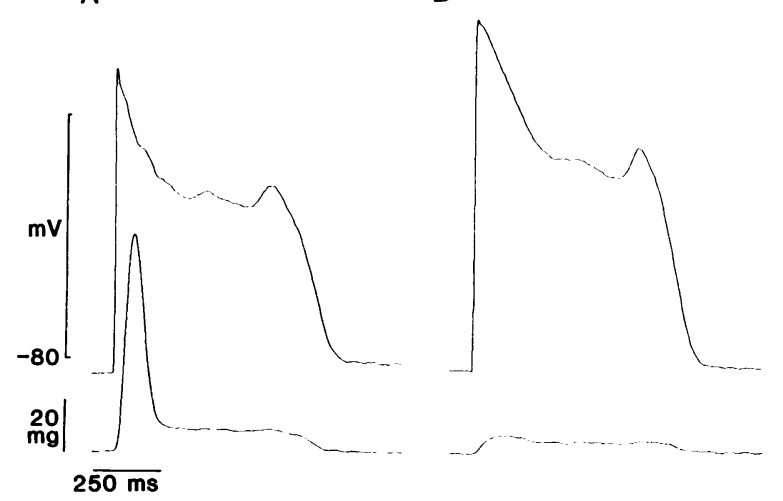

Figure 7. Early afterdepolarizations induced by Cs: effect of ryanodine. $(A)$ Membrane potential (top) and tension during washoff of 10 $\mathrm{mM} \mathrm{Cs}$, in $4 \mathrm{mM}\left[\mathrm{Ca}^{2+}\right]_{0}$. (B) After $12 \mathrm{~min}$ of exposure to $10^{-6} \mathrm{M}$ ryanodine (steady state ryanodine effect).

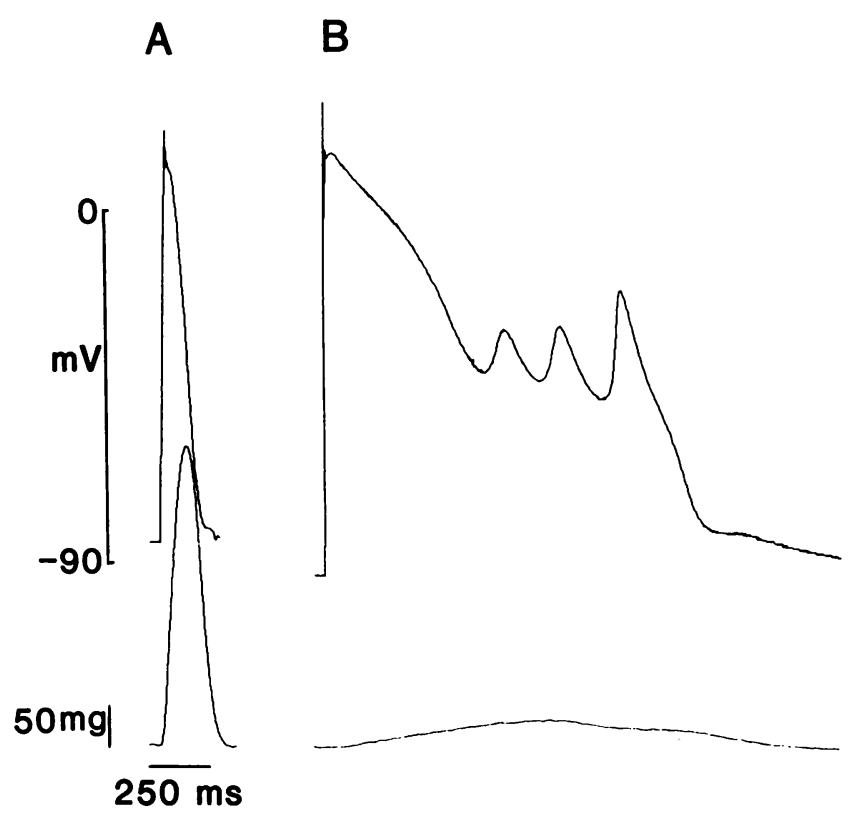

Figure 8. Inducibility of EADs after BAPTA-loading. $(A)$ Control action potential and force. $(B)$ Action potential and force 15 min after exposure to BAPTA-AM ( $2 \mathrm{mM}$ for $10 \mathrm{~min}$ ), just after exposure to 25 mM Cs. $30^{\circ} \mathrm{C}$.

trendipine, on the other hand, decreases open state probability and therefore acts predominantly as an antagonist (25). If the EAD is generated as a direct result of the opening of Ca channels, then Bay K8644 would be expected to potentiate the EAD, whereas nitrendipine would have the opposite effect. These simple predictions are complicated by the fact that changes in $\mathrm{Ca}$ channel activity can have indirect effects by influencing cellular $\mathrm{Ca}^{2+}$ loading. To minimize any possible contribution of changes of $\left[\mathrm{Ca}^{2+}\right]_{i}$ to the observed effects of Bay K8644 and nitrendipine, the effects of these compounds were tested during exposure to ryanodine or after loading with $\mathrm{Ca}^{2+}$ chelators.

Fig. 9 shows the effects of Bay K8644 and nitrendipine on a muscle loaded with $\mathrm{Ca}^{2+}$ buffer. Twitch tension in the control state is shown in panel $A$. The preparation was then loaded with $2 \mathrm{mM}$ quin2-AM and exposed to $25 \mathrm{mM}$ Cs. Quin2 reduced twitch force $(B)$, in an analogous manner to BAPTA. The action
A

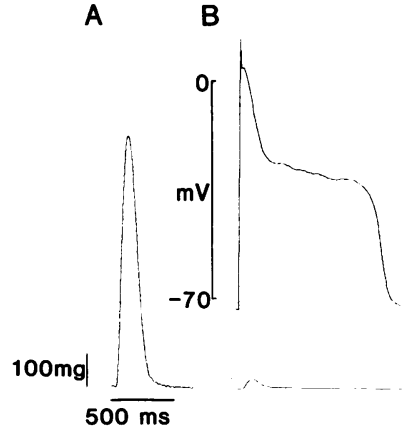

C

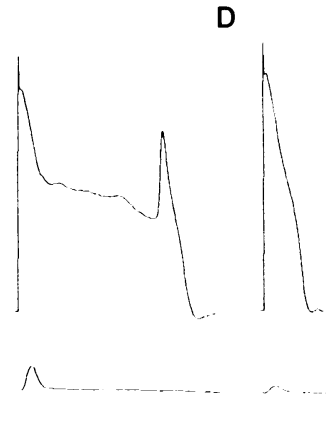

Figure 9. Effects of $\mathrm{Ca}$ channel agonist and antagonist on EADs in quin2-loaded ventricular muscle. $(A)$ Twitch tension in control solution. Membrane potential recordings during this time were unstable due to the strong contraction, and are not displayed. $(B)$ Action potential and force after multiple exposures to $2 \mathrm{mM}$ quin2-AM, within 2 min of washing out $25 \mathrm{mM} \mathrm{Cs}$. (C) $5 \mathrm{~min}$ after addition of Bay $\mathrm{K} 8644(100 \mathrm{nM})$ to the superperfusate. (D) 4 min after removal of Bay $\mathrm{K} 8644$ and addition of nitrendipine $(3 \mu \mathrm{M})$ to the superfusate. $30^{\circ} \mathrm{C}$. 
potential after quin2-loading and exposure to Cs $(B)$ was prolonged but did not exhibit a clear-cut EAD. The addition of Bay $\mathrm{K} 8644$ (100 nM) elicited a large $\operatorname{EAD}(C)$. Bay K8644 was then removed from the bathing solution and substituted by nitrendipine $(3 \mu \mathrm{M})$. Nitrendipine promptly abolished the EAD and abbreviated the action potential $(D)$.

The simplest explanation of these results is that the dihydropyridine compounds increase (or decrease) the current flowing through $\mathrm{Ca}$ channels and thereby facilitate (or abolish) the EAD. Still, an indirect effect via changes in $\left[\mathrm{Ca}^{2+}\right]_{i}$ cannot be excluded in this type of experiment; small changes in twitch tension accompanied exposure to Bay K8644 or nitrendipine (Fig. 9), despite the increased $\mathrm{Ca}^{2+}$ buffering capacity of the cytoplasm. For this reason, we devised a protocol in which the direct sarcolemmal effects of the $\mathrm{Ca}$ channel ligands would be favored over any possible indirect effects mediated by changes in $\left[\mathrm{Ca}^{2+}\right]_{\mathrm{i}}$. In the presence of ryanodine $(1 \mu \mathrm{M})$ and after exposure to $10 \mathrm{mM} \mathrm{Cs}$, we elicited a train of EADs after a 2-min period of quiescence (Fig. $10 \mathrm{~A}$ ). Stimulation was then discontinued, and nitrendipine $(20 \mu \mathrm{M})$ was applied during a second quiescent interval of 2 min duration. The application of nitrendipine during quiescence allowed time for binding to $\mathrm{Ca}$ channels, but presumably did not affect $\left[\mathrm{Ca}^{2+}\right]_{i}$. Stimulation was then resumed, and the first action potential train after quiescence was sampled. An immediate inhibition of the EADs was apparent, as shown in Fig. $10 \mathrm{~B}$. The results of this and three other similar experiments suggest that dihydropyridines alter the channels responsible for the EAD directly, and not as a consequence of changes in $\left[\mathrm{Ca}^{2+}\right]_{i}$.

\section{Discussion}

Our results support the hypothesis that DADs arise from a membrane current activated by intracellular $\mathrm{Ca}^{2+}$. Although the importance of increased $\left[\mathrm{Ca}^{2+}\right]_{i}$ in activating the current is clear, the experiments were not designed to distinguish whether the current itself is generated by an ionic conductance pathway on the one hand $(5,26)$, or an electrogenic ion countertransporter (6) on the other. Either type of transmembrane pathway would be capable of generating a depolarizing current in response to an increase in $\left[\mathrm{Ca}^{2+}\right]_{i}$.

Although our experiments confirm the overall correlation between $\left[\mathrm{Ca}^{2+}\right]_{\mathrm{i}}$ and DADs, a more detailed quantitative analysis would be desirable. Unfortunately, such analysis is not yet fea-
A

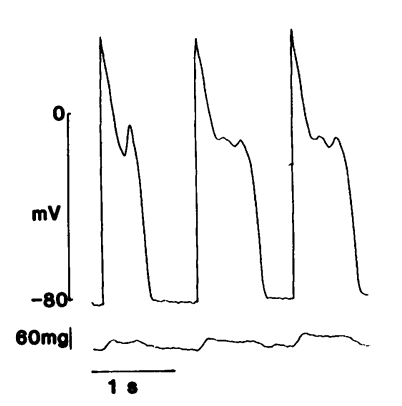

B

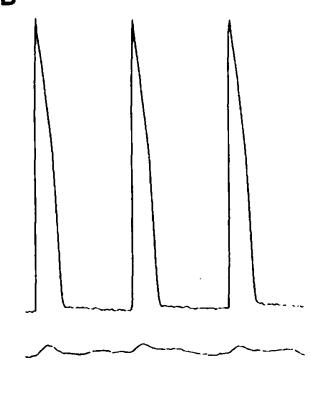

Figure 10. Nitrendipine inhibits EADs after application during quiescence. $(A)$ EADs induced after exposure to Cs $(10 \mathrm{mM})$, in the presence of $1 \mu \mathrm{M}$ ryanodine (steady state effect). The three action potentials are from a stimulated train after 2 min of quiescence. (B) Action potentials elicited after application of nitrendipine $(20 \mu \mathrm{M})$ during 2 min of quiescence. sible. Intracellular $\left[\mathrm{Ca}^{2+}\right]$ is known to be distributed inhomogeneously in mammalian heart cells during $\mathrm{Ca}^{2+}$ overload; at any given time, some areas of each cell have a very high $\left[\mathrm{Ca}^{2+}\right]_{i}$, while $\left[\mathrm{Ca}^{2+}\right]_{\mathbf{i}}$ in other areas of the same cell remains low $(10$, 27). These spatial gradients vary with time, so that $\left[\mathrm{Ca}^{2+}\right]_{i}$ in any given subcellular region undergoes wide fluctuations. Conventional techniques for measuring $\left[\mathrm{Ca}^{2+}\right]_{i}$ lack spatial resolution, yielding only an estimate of spatially averaged $\left[\mathrm{Ca}^{2+}\right]_{i}$. The presence of spatiotemporal $\left[\mathrm{Ca}^{2+}\right]_{i}$ inhomogeneity means that there can be no unique relationship between spatially averaged $\left[\mathrm{Ca}^{2+}\right]_{i}$ and $\left[\mathrm{Ca}^{2+}\right]_{\mathrm{i}}$-dependent processes such as the DAD (28). Reliable quantitative analysis of the relationship between $\left[\mathrm{Ca}^{2+}\right]_{i}$ and the DAD will have to await the refinement of techniques that can resolve $\left[\mathrm{Ca}^{2+}\right]_{i}$ on a subcellular level; one promising approach now under development couples digital imaging microscopy with measurements of fura-2 fluorescence in single heart cells (27).

Several lines of evidence argue against transsarcolemmal $\mathrm{Ca}^{2+}$ entry as the origin of the DAD. Our finding that the DAD is antagonized by agents targeted at intracellular $\mathrm{Ca}^{2+}$ is not consistent with a primary role for $\mathrm{Ca}^{2+}$ entry. Voltage clamp experiments with ryanodine (15) or with intracellular $\mathrm{Ca}^{2+}$ chelators (29) indicate that $\mathrm{Ca}$ channel current is not decreased by these maneuvers, and may even be augmented $(30,31)$. If DADs were generated directly by flow through sarcolemmal $\mathrm{Ca}$ channels, they would be either unaffected or potentiated by ryanodine and BAPTA. The previously noted antagonism of DADs by $\mathbf{C a}$ channel blockers $(4,5)$ can be explained by proposing that $\mathrm{Ca}$ channel blockade ameliorates the $\mathrm{Ca}$ overload state, thereby indirectly decreasing $\left[\mathrm{Ca}^{2+}\right]_{i}(5)$.

Ryanodine and BAPTA eliminate the DAD, but leave behind a slowly repolarizing diastolic "tail" of membrane potential (most apparent in Figs. $3 B$ and $5 B$ ). A similar phenomenon occurs in the canine coronary sinus in response to ryanodine (23). This tail may arise from slowing of the decay of the $\mathrm{Ca}^{2+}$ transient (17), with a consequent change in the pattern of activation of $\left[\mathrm{Ca}^{2+}\right]_{\mathrm{i}}$-dependent membrane currents. Indeed, a slow decay of force accompanies the tail of membrane potential (Figs. $3 B$ and $5 B$ ), substantiating the idea that $\left[\mathrm{Ca}^{2+}\right]_{\mathrm{i}}$ is declining gradually.

Ionic basis of early afterdepolarizations. The lack of inhibition of Cs-induced EADs by ryanodine and by $\mathrm{Ca}^{2+}$ chelators argues strongly that a transient increase in $\left[\mathrm{Ca}^{2+}\right]_{i}$ is not obligatory in the pathogenesis of these events. Our findings are not consistent with the proposal (10) that DADs and EADs share a common basis in intracellular $\left[\mathrm{Ca}^{2+}\right]$ oscillations. If anything, EADs seemed larger and easier to induce after exposure to agents that antagonize oscillations of $\left[\mathrm{Ca}^{2+}\right]_{\mathrm{i}}$. Our results with Bay $\mathrm{K} 8644$ and nitrendipine indicate that EADs arise as a direct consequence of $\mathrm{Ca}^{2+}$ entry through sarcolemmal $\mathrm{Ca}$ channels. If so, the potentiation of EADs by ryanodine and by $\mathrm{Ca}^{2+}$ chelators may be attributable to a reduction of $\mathrm{Ca}^{2+}$-dependent $\mathrm{Ca}$ channel inactivation $(31,32)$ by these agents.

Previous studies examining the ionic basis and pharmacologic sensitivity of EADs have reached a variety of seemingly inconsistent conclusions. Slow Ca channels have been implicated in the genesis of EAD-like repetitive activity elicited in guinea pig papillary muscles by passing depolarizing current across a sucrose gap: Katzung (33) found that elevated $\left[\mathrm{Ca}^{2+}\right]_{0}$ potentiated these oscillations, whereas Imanishi and Surawicz (34) found that they were increased by isoproterenol and antagonized by manganese. On the other hand, studies of EADs in Purkinje fibers have implicated a tetrodotoxin-sensitive pathway for the excitatory inward current $(9,18,35)$. The discrepancies may 
reflect genuine differences in the ionic channels of ventricular and Purkinje tissue. Ventricular muscle has larger $\mathrm{Ca}$ currents (and presumably more functional Ca channels) than Purkinje fibers $(19,36)$, whereas the converse is true for TTX-sensitive $\mathrm{Na}$ channels (37).

A unifying concept has been put forward by Hoffman and Rosen (3) “. . . all that is needed to cause repetitive firing from an early afterdepolarization is a sufficient decrease in $\mathrm{K}^{+}$conductance relative to the conductance for inward current." In this framework, our results can be explained by the proposal that $\mathrm{Cs}$ decreases $\mathrm{K}^{+}$conductance, allowing the slow $\mathrm{Ca}$ channel conductance to predominate. It must be emphasized that, under other experimental conditions, $\mathrm{Na}$ channels may carry the depolarizing current. In a computer simulation of EADs based on the McAllister, Noble, and Tsien model (38), Coulombe and co-workers (39) predicted that either $\mathrm{Na}$ conductance or slow Ca conductance could support secondary depolarizations, depending on the detailed assumptions. Because EADs can be quite variable, the conclusions we have reached regarding $C s$-induced EADs in ventricular muscle should not be extrapolated to other tissues or interventions. On the other hand, a similar approach could be used to assess the roles of $\left[\mathrm{Ca}^{2+}\right]_{\mathrm{i}}$ and $\mathrm{Ca}$ channels in the pathogenesis of other types of afterpotentials.

Finally, the approach of loading with membrane-permeable $\mathrm{Ca}^{2+}$ chelators may prove useful in other applications in multior unicellular cardiac preparations, as a way of selectively manipulating intracellular $\mathrm{Ca}^{2+}$ without disrupting the sarcolemma.

\section{Acknowledgments}

We thank Dr. Joseph Levine for helpful discussions.

Supported by National Institutes of Health (NIH) grant HL-29473 (to Dr. Wier). Dr. Marban is the recipient of a Research Career Development Award of the NIH. Dr. Robinson was the recipient of a Medical Student Research Fellowship of the American Heart Association.

\section{References}

1. Cranefield, P. F. 1975. The conduction of the cardiac impulse. Futura Press, Mount Kisco, NY. 332 pp.

2. Ferrier, G. R., and G. K. Moe. 1973. Effect of acetylstrophanthidininduced transient depolarizations in canine Purkinje tissue. Circ. Res. 33:508-515.

3. Hoffman, B. F., and M. R. Rosen. 1981. Cellular mechanisms for cardiac arrhythmias. Circ. Res. 49:1-15.

4. Rosen, M. R., and P. Danilo. 1980. Effects of tetrodotoxin, lidocaine, verapamil, and AHR-2666 on ouabain-induced delayed afterdepolarizations in canine Purkinje fibres. Circ. Res. 46:117-124.

5. Kass, R. S., W. J. Lederer, R. W. Tsien, and R. Weingart. 1978. Role of calcium ions in transient inward currents and after contractions produced by strophanthidin in cardiac Purkinje fibres. J. Physiol. (Lond.). 281:187-208

6. Karaguezian, H. R., and B. G. Katzung. 1982. Voltage-clamp studies of transient inward current and mechanical oscillations induced by ouabain in ferret papillary muscle. J. Physiol. (Lond.). 327:255-271.

7. Damiano, B. P., and M. R. Rosen, 1984. Effects of pacing on triggered activity induced by early afterdepolarizations. Circulation. 69(5): 1013-1025.

8. Levine, J. H., J. F. Spear, T. Guarnieri, M. L. Weisfeldt, C. D. J. De Langen, L. C. Becker, and N. Moore. 1985. Cesium chloride-induced long QT syndrome: demonstration of afterdepolarizations and triggered activity in vivo. Circulation. 72(5):1092-1103.

9. Brachmann, J., B. J. Scherlag, L. V. Rosenshtraukh, and R. Lazzara. 1983. Bradycardia-dependent triggered activity: relevance to drug-induced multiform ventricular tachycardia. Circulation. 68(4):846-856.

10. Capogrossi, M., and E. G. Lakatta. 1985. Frequency modulation and synchronization of spontaneous oscillations in cardiac cells. Am. J. Physiol. 248:H412-H418.

11. Moak, J. P., and M. R. Rosen. 1984. Induction and termination of triggered activity by pacing in isolated canine Purkinje fibres. Circulation. 69(1):149-162.

12. Sutko, J. L., J. T. Willerson, G. H. Templeton, L. R. Jones, and H. R. Besch. 1979. Ryanodine: its alteration of cat papillary muscle contractile state and responsiveness to inotropic interventions and a suggested mechanism of action. J. Pharmacol. Exp. Ther. 209:37-47.

13. Wier, W. G., A. A. Kort, M. D. Stern, E. G. Lakatta, and E. Marban. 1983. Cellular calcium fluctuations in mammalian heart: direct evidence from noise analysis of aequorin signals in Purkinje fibers. Proc. Natl. Acad. Sci. USA. 80:7367-7371.

14. Valdeolmillos, M., and D. A. Eisner. 1985. The effects of ryanodine on calcium-overloaded sheep cardiac Purkinje fibers. Circ. Res. 56: 452-456.

15. Sutko, J. L., and J. L. Kenyon. 1983. Ryanodine modification of cardiac muscle responses to potassium free solutions: evidence for inhibition of sarcoplasmic reticulum calcium release. J. Gen. Physiol. 82:385-404.

16. Tsien, R. Y. 1980. New calcium indicators and buffers with high selectivity against magnesium and protons: design, synthesis, and properties of prototype structures. Biochemistry. 19:2396-2404.

17. Wier, W. G., D. T. Yue, and E. Marban, 1985. Effects of ryanodine on intracellular $\mathrm{Ca}^{2+}$ transients in mammalian cardiac muscle. Fed. Proc. 44:2989-2993.

18. Roden, D. M., and B. F. Hoffman. 1985. Action potential prolongation and induction of abnormal automaticity of low quinidine concentration in canine Purkinje fibers: relationship to potassium and cycle length. Circ. Res. 56:857-867.

19. Marban, E., and R. W. Tsien. 1982. Effects of nystatin-mediated intracellular ion substitution on membrane currents in calf Purkinje fibres. J. Physiol. (Lond.). 329:569-587.

20. Tsien, R. Y. 1981. A non-disruptive technique for loading calcium buffers and indicators into cells. Nature (Lond.). 290:527-528.

21. Blinks, J. R., W. G. Wier, P. Hess, and F. Prendergast. 1982. Measurement of $\mathrm{Ca}^{2+}$ concentration in living cells. Prog. Biophys. Mol. Biol. 40:1-114.

22. Gavrilescu, S., and C. Luca. 1978. Right ventricular monophasic action potentials in patients with long QT syndrome. Br. Heart J. 40: 1014-1018.

23. Aronson, R. S., P. F. Cranefield, and A. L. Wit. 1985. The effects of caffeine and ryanodine on the electrical activity of the canine coronary sinus. J. Physiol. (Lond.). 368:593-610.

24. Wier, W. G., and P. Hess. 1984. Excitation-contraction coupling in cardiac Purkinje fibers: effects of cardiotonic steroids on the intracellular $\left[\mathrm{Ca}^{2+}\right]$ transient, membrane potential and contraction. J. Gen. Physiol. 84:395-415.

25. Hess, P., J. Lansman, and R. W. Tsien. 1984. Different modes of $\mathrm{Ca}$ channel gating behavior favoured by dihydropyridine $\mathrm{Ca}$ agonists and antagonists. Nature (Lond.). 311:453-456.

26. Colquhoun, D., E. Neher, H. Reuter, and C. F. Stevens. 1981. Inward current channels activated by intracellular $\mathrm{Ca}$ in cultured cardiac cells. Nature (Lond.). 294:752-754.

27. Berlin, J., M. Cannell, W. Goldman, W. J. Lederer, E. Marban, and W. G. Wier, 1986. Subcellular calcium inhomogeneity indicated by fura-2 develops with calcium overload in single rat heart cells. J. Physiol. (Lond.). 371:200P.

28. Kort, A. A., E. G. Lakatta, E. Marban, M. D. Stern, and W. G. Wier. 1985. Fluctuations in intracellular [Ca] and their effect on tonic tension in canine cardiac Purkinje fibres. J. Physiol. (Lond.). 367:291308 .

29. Marban, E., and R. W. Tsien. 1982. Enhancement of calcium current during digitalis inotropy in mammalian heart: positive feed-back regulation by intracellular calcium? J. Physiol. 329:589-614.

30. Mitchell, M. R., T. Powell, D. A. Terrar, and V. W. Twist. 1984 
Ryanodine prolongs Ca-current while suppressing contraction in rat ventricular muscle cells. Br. J. Pharmacol. 81:13-15.

31. Josephson, I. R., J. Sanchez-Chapula, and A. M. Brown. 1984. A comparison of calcium currents in rat and guinea pig single ventricular cells. Circ. Res. 54:144-156.

32. Lee, K. S., E. Marban, and R. W. Tsien. 1985. Inactivation of calcium channels in mammalian heart cells: joint dependence on membrane potential and intracellular calcium. J. Physiol. (Lond.). 364:395411.

33. Katzung, B. G. 1975. Effects of extracellular calcium and sodium on depolarization-induced automaticity in guinea pig papillary muscle. Circ. Res. 37:118-127.

34. Imanishi, S., and B. Surawicz. 1976. Automatic activity in depolarized guinea pig ventricular myocardium. Circ. Res. 39:751-759.
35. Marchese, A. C., J. A. Hill Jr., P.-D. Xie, and H. C. Strauss. 1984. Electrophysiologic effects of amiloride in canine Purkinje fibers: evidence for a delayed effect on repolarization. J. Pharmacol. Exp. Ther. 232:485-491.

36. Isenberg, G. 1982. Ca entry and contraction as studied in isolated bovine ventricular myocytes. Z. Naturforsch. 37c:502-512.

37. Bean, B. P., C. J. Cohen, and R. W. Tsien. 1983. Lidocaine block of cardiac sodium channels. J. Gen. Physiol. 81:613-642.

38. Mc Allister, R. E., D. Noble, and R. W. Tsien. 1975. Reconstruction of the electrical activity of cardiac Purkinje fibers. J. Physiol. (Lond.). 251:1-59.

39. Coulombe, A., E. Coraboeuf, and E. Deroubaix. 1980. Computer simulation of acidosis-induced abnormal repolarization and repetitive activity in dog Purkinje fibers. J. Physiol. (Paris). 76:107-112. 